\title{
Europe plots comeback in neutron science
}

\section{David Adam, London}

Researchers are laying plans to wrestle back Europe's leadership in neutron science after powerful neutron-scattering facilities open in the United States and Japan in a few years' time. This summer, the Europeans are putting the finishing touches to plans for a new $\mathfrak{E} 1$-billion (US\$1.5-billion) neutron facility of their own.

Two of the three key issues underpinning the design of the proposed European Spallation Source (ESS) were resolved at a UK meeting of project planners in Abingdon on 15 June. A final plan will be submitted to European governments and funding agencies by 2003, and ESS supporters hope to obtain permission to start work on the project the following year.

Neutron sources can be used to probe the structure of anything from superconducting materials to proteins, and are therefore an essential tool for physicists, chemists, materials scientists and structural biologists. The interaction of neutrons with light atoms such as hydrogen allows some structures to be examined more effectively than with other techniques, such as X-ray diffraction.

Scientists planning the ESS say it will be more powerful than both the US Spallation Neutron Source, now under construction at the Oak Ridge National Laboratory in Tennessee, and the planned Japanese spallation neutron source. Europe currently has a clear lead in neutron-scattering science. It is home to the world's two most powerful neutron sources - at the Institut Laue Langevin in Grenoble, France, and ISIS near Oxford in England - and around two-thirds of the discipline's scientific community.

But it could lose some of that lead when the US and Japanese projects, both of which will be more powerful than anything in Europe, open within six years. Even if the ESS is approved in 2004, it will not be operational until at least 2011.

That five-year window will blunt Europe's leadership in the field, predicts Bob Cywinski, a physicist at the University of Leeds who chairs the European Neutron Scattering Association. "We will still be able

\section{Gene screens for nuclear veterans}

\section{Peter Pockley, Sydney}

New Zealand veterans of British nuclearweapons tests are to be tested for genetic abnormalities. The New Zealand Nuclear Test Veterans' Association said last month that it will conduct a pilot analysis of DNA from 50 veterans.

Around 40,000 troops witnessed or assisted in the 1952-58 tests, which took place in and around Australia and on Christmas Island, and involved $528 \mathrm{New}$ Zealand sailors, with most of the others

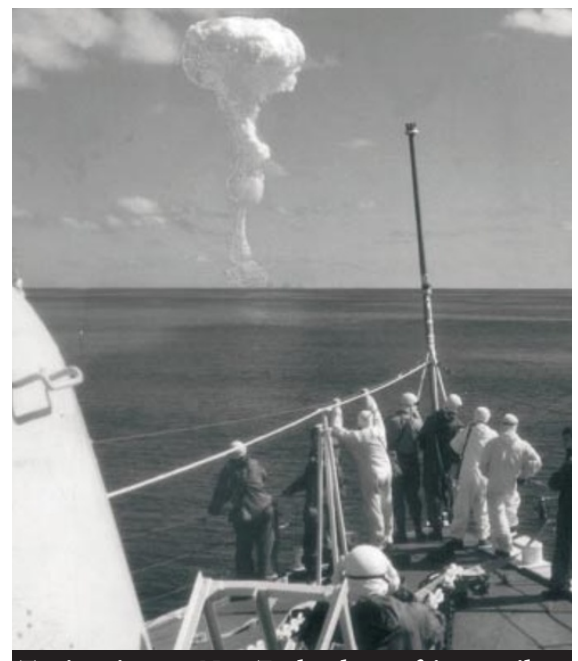

Testing times: a New Zealand navy frigate sails into the wake of a British H-bomb explosion. coming from Britain and Australia.

Those involved have long complained that the effects have never been fully investigated. The New Zealand veterans claim that their life expectancy has been reduced by at least 10 years, and that there is an unusually high rate of genetic disorders among them and their children.

"Rightly or wrongly, the men who were exposed to the nuclear tests perceive that they now suffer from a range of illnesses that is different from the normal population," says Al Rowland, a cytogeneticist at Massey University in North Palmerston, New Zealand, who will carry out the tests.

Rowland will use stem cells from veterans' bone marrow to look for chromosome damage. In parallel, John Podd, a psychologist from Massey University, will assess the long-term psychological effects of the nuclear trials.

The Australian government also plans to compare the health of the nation's 18,000 test veterans - a full list of whose names was published last month for the first time with that of the general population.

The New Zealand veterans' association is planning legal action against the British government for allegedly neglecting its duty of care. Previous claims by individuals have been unsuccessful or settled out of court, with no admission of fault by the government.

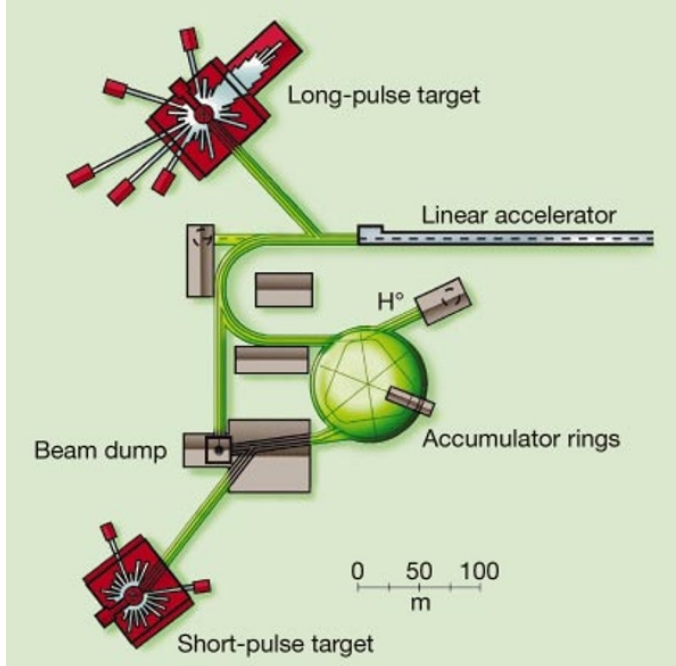

Target set-up: the ESS proton stream will be accelerated in the direction of two targets.

to do high-class science, but we will not be at the cutting edge and that is a dangerous scenario," Cywinski says. "And if the ESS does not get built at all then we might as well give up and go home."

If the ESS is constructed, it will be a standalone facility dedicated solely to neutron scattering. Spallation sources produce neutrons by first generating a stream of highenergy protons that are crashed into a metal target, chipping off neutrons from the nuclei of the metal atoms. Researchers had suggested that some of the protons produced might be diverted into other projects, such as experimenting with the transmutation of nuclear waste. But the ESS council now says that "strategic considerations" make that option unworkable.

Cywinski is pleased with the decision. "If you have an accelerator that is doing many things, then there is always the suggestion that it might be a compromise and we don't want to compromise the ESS in any way," he says.

The ESS council meeting also decided on the facility's configuration (see figure, above). It has been decided that the proton supply will be directed at two targets - one beam will strike in short proton pulses of 50 hertz and the other in longer, 16.67hertz pulses.

The third issue, still to be decided, is the specific nature of the proton accelerator that will drive the particles at energies high enough to splinter the metal target atoms.

The site of the ESS is also unresolved, although the existing Forschungszentrum research facility in Jülich, Germany - where the ESS administration is based - is an early favourite. Peter Tindemans, the ESS council chairman, says that interested countries will soon be asked to submit bids. 